\title{
HR practices in the context of the Internet of Things
}

\author{
Kristian Kremer \\ University of Pécs, Pécs, Hungary \\ https://orcid.org/0000-0002-9051-9038
}

\begin{abstract}
In an increasingly competitive business environment, it has become important for business organizations to equip themselves with the latest technologies. The Internet of Things (IOT) is considered to be one of the major emerging technologies. By connecting physical objects with the internet, the loT allows things or smart objects to operate autonomously in a context-adequate way. There is a broad range of business application domains for the loT. However, most of the research initiatives focus on technological issues in the context of logistics, manufacturing, retailing, and healthcare. That is why it seems to be important to elaborate on application possibilities of the loT in human resource management (HRM). The present paper aims at providing a perspective on how the application of the loT can be used to improve core HR practices.
\end{abstract}

\section{Keywords}

human resource management, Internet of Things, technology, human resource practices

\section{Introduction}

Along with the internet and technological growth, the Internet of Things (IoT) induces a technological paradigm shift, which connects anyone and anything at any place and any time (Baldini, Botterman \& Tallacchini, 2018). The vision of the IoT is that of a smart world full of smart components and sensing technologies. The IoT involves users much more deeply as they are more strongly connected with technology going beyond creating and sharing content (Kreps \& Kimppa, 2015). Hence, it is no surprise that such a bold vision, along with its potential to underpin innovative applications and services, has captured the attention of both practitioners and academics. Indeed, executives believe the IoT to be the most relevant emerging technology, ranking it above artificial intelligence or robotics (Insights Team, 2017). As societal norms and business models will be challenged, the IoT is expected making a major impact on businesses and individuals (Stankovic, 2014).

There is a broad range of business application domains for the IoT, such as logistics, manufacturing, retailing, and healthcare. Since large changes with many opportunities and threats are expected in these domains, plenty of research initiatives come along with the growing application of the IoT. The probably most prominent example is manufacturing research. Smart manufacturing is nowadays widely accepted as the new paradigm of manufacturing (Thoben, Wiesner \& Wuest, 2017).

In contrast to these developments, it must be noted that the IoT does not appear being a topic of major interest in the domain of human resource management (HRM) with only very few publications existing on this topic (Bondarouk, Parry \& Furtmueller, 2017). While most of the IoT studies are focusing on technological issues, this paper pays attention to possibilities and consequences that the IoT offers for HRM.

To ensure a clearer understanding of the topic under review, the first two parts of this paper serve as a theoretical foundation by providing an overview of the concept IoT, along with an elaboration of the main challenges arising from it. Next, the evolution of the IoT in the context of HRM is being outlined. This is followed by a 
discussion on the role of HR technology for the IoT. After that, the methodology is described. This is followed by the results of the analyses on HR practices on which the application of the IoT might has a relevant impact on. This is followed by a discussion of the results and conclusions.

\section{Literature review}

\subsection{Internet of Things}

While the term IoT is nowadays used widely, there is no common understanding or definition existing on what the concept of IoT encompasses. However, regardless of variations in the definition, the objective of the IoT is similar in a broad sense. Atzori, Iera and Morabito (2010) approach the concept of IoT with three visions, including internet-oriented, things-oriented, and semantic-oriented visions. The authors further conclude that the IoT addresses uniquely objects that can react to their physical environment as well as interact with other objects to reach common objectives.

Another definition by ITU (2012) suggests that the IoT includes all objects of the virtual or physical world that can be identified as well as integrated into networks of communication. One of the probably most comprehensive definitions is proposed by the European Commission. It conceptualizes the IoT by the two words internet and thing. While internet constitutes a network of interconnected computer systems, thing is an object not exactly identifiable. Hence, the IoT represents a world-wide network of interconnected objects. In other words, the IoT allows connecting people and things at any place and any time, with anyone and anything, using any service and any network (Guillemin \& Friess, 2009).

The definitions have a certain amount of overlapping and share a few similar characteristics. Basically, the IoT aims at ensuring an efficient sharing of information among autonomous actors within a network in real time (Yang, Yang, \& Plotnick, 2013). According to Stankovic (2014), the IoT refers to the connection of countless intelligent and communicating objects in an internet structure as part of a future smart world. Objects of the future smart world can uniquely be identified and accessed via the internet. They will be virtually represented in a cyberspace, enabling an interaction between humans and objects, or between objects (Andersson \& Mattsson, 2015).
Interconnected objects build a network not only harvesting digital information, but also interacting with the physical world. Thus, as well as extending internet advantages to the physical world, including constant connectivity, data sharing, and remote control the IoT merges the digital and physical world (Shin, 2014). The IoT architecture will facilitate the exchange of services and goods and bring new opportunities for service innovation (Winter, 2014). By creating a society of interconnected devices, social systems are moving forward towards full connectivity. Hence, it is no surprise that the IoT is expected to lead to a new technological paradigm and introduce a social shift (Elmaghraby \& Losavio, 2014).

\subsection{Internet of Things challenges}

Although the IoT will certainly create many new possibilities, there are various challenges arising from continuous automation and digitization at the same time. Due to a massive increase of data collected by IoT devices, data centers will face challenges in server technologies, data center networking, storage management, data itself, security, and consumer privacy (Gartner, 2014). The main challenges related to data management, data mining, privacy, and security are being outlined in the following.

IoT devices and sensors create large amounts of data, which need to be stored and processed. However, current data center architectures are usually not prepared to deal with sheer volume of business and personal data, which are very heterogeneous in nature (Gartner, 2014). Lee and Lee (2015) argue that only few organizations are capable to sufficiently invest in respective capacities to store all the IoT data gathered. In consequence, organizations must prioritize operational data or prioritize data based on value and needs. Since IoT devices become more widely used and are consuming more bandwidth, data centers must become increasingly distributed to improve response time and processing efficiency.

Due to the growing amount of data available for analysis, the utilization of data mining tools becomes necessary. Besides traditional data, streaming data are increasingly collected, generated by digital sensors in electrical meters, industrial equipment, automobiles, or shipping crates. Data mining tools can initiate corrective measures that immediately address operational issues or inform managers of findings that will 
impact short- and long-term business activities (Lee \& Lee, 2015). According to Manyika et al. (2011), data need to be approached by using advanced technologies and statistical techniques. Since traditional techniques related to data mining are not directly usable for unstructured data, such as images and videos, there is a need for advanced data mining tools that are able to mine these kinds of data. This, in turn, calls for data analysts with the respective skills and managers who can make business decisions based on evidence.

IoT devices can provide large amounts of user data related to movements, purchasing preferences, and health conditions - all of them raising data privacy concerns. In this scenario, protecting privacy is often counter-productive, as data generated by the IoT decreases the costs of the service provider by streamlining processes and is likely to enhance people's life quality. However, according to a TRUSTe survey (2014), only 22 percent of internet users agree that advantages of smart objects outweigh concerns in regards to privacy. While the concept of the IoT gains momentum through wearable devices and smart systems, it is obvious that the acceptance and confidence in the IoT will greatly depend on the privacy protection of users (Lee \& Lee, 2015).

The potential security threats are about to escalate due to an increasing variety and number of connected IoT devices. While the IoT improves the productivity of organizations and is likely to enhance people's quality of life, it will also increase a potential attack by cyber criminals. According to a study by Hewlett Packard (2014), 70 percent of the most used IoT devices show significant weaknesses due to insecure web interfaces, inadequate software protection, lack of encryption, and insufficient authorization. Lee and Lee (2015) argue that challenges related to security may be resolved, if developers incorporate security solutions into products and users utilize security features. However, failing to do so will build resistance to the adoption of the IoT.

\subsection{Evolution of Internet of Things in HRM}

Smart things enable the automation of tasks that were not automatable before, due to their complex physical-motoric and perceptive-cognitive requirements (Borgia, 2014). Increasing automation potentials with the possibility to manage security, efficiency, and objectivity with higher transparency and without bias are to be expected when applying the IoT in HRM.
Although researchers have been carried out studies measuring the relevance of technology for HRM, only a limited studies are dealing with the application of the IoT in the HRM context (Bondarouk et al., 2017).

In the advent of the IoT, more recent research has shifted towards smart things. According to a study by Gluhak et al. (2011), fundamental changes are needed in work place management to pave the way for the IoT. Weinberger, Bilgeri and Fleisch (2016) introduced the high-resolution management concept, which measures all kind of business operation aspects in an industrial context. According to the authors, organizations that are applying high resolution management (e.g., measuring operational activities in real time) achieved more flexibility, efficiency, and quality. Bauk, Dlabač and Škurić (2018) studied high resolution management to establish business models for the IoT, including digital add-on, object self-service, digital lock-in, and physical freemium. The authors conclude that the IoT enables the development of innovative business models, besides enhancing the overall quality of products and business processes.

Research exploring the linkage between IoT and HRM is mainly concerned with increased automation potentials that can be expected by applying the IoT in HRM. Potential scenarios refer to the employment of smart things for HRM information, such as sensing HR information including staffing requirements, qualification deficits, working times, or break needs (e.g., Bersin, Mariani \& Monahan, 2016). Smart tools can also be used in training and development, by introducing new users in a fully automated manner to tool handling and application (Charmonman, Mongkhonvanit, Dieu, \& Linden, 2015; Dlodlo, 2012). Besides, smart things can also be used for workforce planning in manufacturing companies. Information on the interaction between work pieces and smart tools can be used to identify the time, quantity, and quality of employees in manufacturing. This, in turn, offers input to create algorithms fully automating manufacturing employees' schedule (Spath, Gerlach, Hämmerle, Schlund, \& Strölin, 2013). Moreover, measuring data related to employee stress, exercise level, physical fatigue, etc. and transforming them into algorithms that provide health suggestions for employees can improve organizational health management (Solanas et al., 2014; Nihan, 2013).

The clearly apparent and increasing 
information potentials are also expected by applying the IoT in HRM. A broad spectrum of HR-relevant data can be generated by sensors that employees wear during work. This kind of information might refer to employees' requirements, qualifications, performance, physical activity, psychological state, or social situation (Waber, 2013).

\subsection{The role of HR technology for Internet of Things}

It seems to be obvious that applying the IoT in HRM will first have an impact on present HR technologies, which have already been subject to ongoing change in the last decades (Stone, Deadrick, Lukaszewski, \& Johnson, 2015). However, the IoT has not been widely utilized in HRM yet. It is first important to understand that data, software, and hardware are the main components of HR technology. Any application of the IoT in HRM is likely to make changes in all the three components, which need to interact with each other to deliver the expected functionalities (Strohmeier, 2020).

Applying the IoT in HRM implies the utilization of various smart things with the purpose to automate certain HR practices or collecting certain HR information. Although IoT technologies have yet rarely been utilized within HRM, it can be assumed that smart things will complement the current HRM hardware infrastructure. In addition, current HR software, which refers to coded instructions run by HR hardware, will need to be modified to realize information and automation potentials of the IoT. Furthermore, the application of the IoT will change and create new data, which refers to information stored, transmitted, and processed by the interaction of software and hardware. In this respect, a strong increase in data speed and volume can be expected because of applying the IoT, expanding the organizational information potentials (Swan, 2012, Fleisch, 2010).

\section{Research methodology}

The methodology applied is a literature review based on the inclusion of research journal papers, conference papers, and books dealing with the concept of the IoT applied in HRM context and specifically with the impact of the IoT on specific HR practices. The review was conducted using academic databases accessed through Google Scholar, Scopus, Web of Science, and EBSCOhost using the terms 'IoT' or 'Internet of
Things' in combination with the terms 'Human Resource Management' or 'HR practices'.

A total of 49 references were added to the literature review. With three exceptions, all the references were published between 2009 and 2020 , underlining the relevance of the theme. It is notable, that all the twelve papers, which are specifically addressing HR practices in the context of the IoT, were published from 2016 on and are either review or survey papers. This emphasizes the relevance of this topic, but also the need for studies that involve testing of theoretically derived hypotheses.

The analysis of the literature revealed six main HR practices on which the IoT might have an impact on. For better transparency, they have been given the following names: workforce planning, recruitment, performance management, training and development, HR Analytics, and health management.

\section{Results and discussion}

HR practices can be referred to a set of activities related to employees, which are performed to ensure the employee quality and quantity an organization needs to achieve its objectives (Ostroff \& Bowen, 2000). While some categorizations of HR practices are existing in the academic literature, like the AMO-framework by Boxall and Purcell (2003), an enormous variability regarding single $\mathrm{HR}$ practices and their categorization can be constituted. However, at least six HR practices can be considered that are both frequently employed in practice and relevant for the success of HR, including workforce planning, recruitment, performance management, training and development, health management, as well as information and decision-related activities, which are nowadays also referred to HR Analytics (Lepak, Liao, Chung, \& Harden, 2006). Although this set of HR practices is necessarily incomplete, it is a starting point for a first exploration of possibilities when applying the IoT in HRM.

\subsection{Workforce planning}

Technology is considered being the main driver for workplace change. The nature of workplace changes along with the collective utilization of cloud-based applications and smart phones, which changes the working environment towards more collaborative workplaces, such as working virtually and from home (Barman \& Das, 2018). Smart phones are one of the most relevant hubs of the IoT, helping organizations to seek suggestions 
and ideas of their employees irrespective of their location. With the help of smart phones, it is possible to implement true flexible working, wherein employees can work anytime and anywhere (Venkatesh, 2017; Hassan, Ali, \& Badawy, 2015). Collaborative workplaces and more flexible ways of working enable organizations to manage their human resources more effectively by reducing operational costs and time to a very large extent. The IoT can act as a catalyst for enhancements in HRM by boosting employee productivity and increasing employee engagement (Barman \& Das, 2018).

The IoT can increase the productivity and effectiveness of employees in many ways. It provides various means of collecting data in an automated way, reducing the possibility of human error (Rose, Eldridge, \& Chapin, 2015). This, in turn, serves as a better foundation for the HR decision-making process, for instance by optimizing employee scheduling to maximize productivity. Employees can be scheduled according to data that pinpoints their most productive periods (Vivekananth, 2016). Indeed, information on the interaction between work pieces and smart tools can be used to identify the time, quantity, and quality of employees in manufacturing. These kinds of data can be used to create algorithms fully automating the scheduling of manufacturing employees (Spath et al., 2013). IoT sensing devices can be attached to workers and to the equipment they are using to record every aspect of employee experience in the organization (Gaur, Shukla, \& Verma, 2019).

\subsection{Recruitment}

The application of the IoT potentially increases the efficiency in regard to the recruitment process. The IoT can optimize all stages of the recruitment process and improve hiring decisions (Gaur et al., 2019). Since in more business domains various smart things are utilized and interact with each other autonomously to support in providing the intended services and products, it can be expected that organizational hiring needs will continuously start to come up in an ad hoc way (Guillemin \& Friess, 2009).

In smart factories, for instance, various smart work pieces are interacting with various smart objects to determine and carry out pending duties in the production. In case a specific work step needs support by an employee with certain skills that are currently not available, smart tools and work pieces report an ad hoc hiring need that has to be met as soon as possible to avoid interruptions in the production process. Hence, the assignment and scheduling of employees are increasingly to be undertaken in real time (Strohmeier, 2020).

Nowadays, job seekers rely heavily on mobile technology to access information on jobs and companies. HR can make use of this technology to increase their visibility on social networks (e.g., LinkedIn), which are increasingly accessed via smart devices (Mohanty \& Mishra, 2020). Moreover, the behavior of applicants in a virtual situation can be assessed, which reduces biases in the decision. Virtual reality situations enable assessing a candidate in dealing with reality during the selection procedure. At the same time, candidates can attend their interviews from home and will receive a more realistic picture of their potential future job (Venkatesh, 2017). However, Strohmeier (2020) argues that using smart things to automate the recruitment process fully might not be technically feasible, since social competencies of the candidates also must be considered.

\subsection{Performance management}

The data accumulated by the IoT can be used to create a closer and more constructive connection between managers and their employees, which potentially enhances the performance management process (Venkatesh, 2017). The additional data gathered by IoT devices can be used to set up more concrete objectives for the employees, which is likely to increase their overall productivity level (Gaur et al., 2019). Organizations can use performance management apps with objective criteria to assess the performance of employees, allowing to provide a digital feedback and keep track of organizational growth in a more convenient and efficient way (Mohanty \& Mishra, 2020).

However, Strohmeier (2020) argues that it might be managerial undesirable using sensors to evaluate the performance of employees in high resolution and real time, since this would imply over surveillance. According to Mohanty and Mishra (2020), one must be careful with data that provide socio-metric measurements on employees' social behavior. These kinds of data should only supplement and not substitute employees' personal identity. 


\subsection{Training and development}

The application of the IoT can help to personalize training programs, which can also be planned, organized, and coordinated based on the additional data gathered by IoT devices (Gaur et al., 2019). The just-in-time training concept has been discussed for quite a while (Iannarelli, 2009). It seems to be obvious that just-in-time training is fostered by the application of the IoT. With respective software, it is possible to continuously track training outcomes, coaching, and feedback of employees, allowing to identify qualification gaps or training deficits in real time (Mohanty \& Mishra, 2020).

Learning management systems will be able to interact with IoT devices to organize and provide training in real time, in case sensors identify qualification deficits of an employee. Necessary training measures are expected to be delivered in real time by sensors attached to smart things, which employees are using. This training acceleration is considered as essential to avoid delays and interruptions in providing services and products (Strohmeier, 2020).

An already elaborated application scenario refers to using smart tools in training and development to introduce new users in a fully automated way to tool handling and application. Another application scenario refers to the increasing utilization of self-services. In this regard, training and development is just one HR area, where smart things can extent HR tasks that employees perform via self-service (Strohmeier, 2020). Dash Farooq, Panda, and Sandhyavani (2019) propose the implementation of an IoT framework for HRM processes that would lead to competency development by deploying IoT sensors and devices. With the help of IoT and other innovative technology, it is feasible to create personalized experiential learning (Pathak \& Solanki, 2021)

\subsection{HR Analytics}

In a business environment that is moving forward towards a quantified workplace and where decisions are made based on data analytics, the IoT potentially enhances the process of quantifying employees' work by gathering and providing useful data on the performance and wellness of employees (Barman \& Das, 2018). The application of the IoT will increase the provision and utilization of information in HRM, which is in line with the present discussion on HR Analytics (e.g., Kremer, 2018). Basically, HR
Analytics refers to the notion that HR decisions and practices should be based on evidence rather than on intuition and conjecture. Since HR Analytics is about systematically gathering and supplying information that is necessary for the decision-making process in HR, it seems to be obvious that increasing sensing functions initiate extensive changes in HR Analytics' related processes and results (Waber, 2013).

According to Vivekananth (2016), the IoT will be applied in HR Analytics to support in assessing HR practices and processes. The IoT will change the way of gathering and analyzing HR data. Professionals in the field of HR Analytics will have to learn about the new kind of data created by IoT devices. HR Analytics professionals will have to comprehend market trends and the costumers to successfully integrate these data into their analyses.

Larger sets of sensors among an increasing number of smart things enable the measurement of various new issues related to HR (Swan, 2012). The quality of HR data is about to increase, since sensors are expected to enhance the quality of measurement in comparison to conventional ways of HR data ascertainment. Moreover, sensors will decrease time span between the happening of an event important for $\mathrm{HR}$ and its information provision, allowing for faster HR decision and service delivery. Due to the increased quantity, quality, and speed of HR data, the overall relevance of HR Analytics is expected to increase (Strohmeier, 2020).

\subsection{Health management}

The health of the employees becomes increasingly important for organizations, since research indicates that healthy employees are more engaged and perform better. Thus, all measures taken by organizations to protect and improve the health of employees is likely to improve the overall productivity of the business. The IoT has the potential to help organizations in gathering data related to employees' health, enabling them to design and implement respective programs to improve the health of employees, which will in turn enhance organizational productivity and profit (Venkatesh, 2017).

The organizational health management can be improved by measuring data related to employee stress, exercise level, physical fatigue, etc. and transforming them into algorithms that provide health suggestions for employees (Strohmeier, 2020). Organizations can provide fitness tracker 
to employees to gather and monitor their health (Venkatesh, 2017). However, these kind of data raises privacy concerns and would need to be used with employee consent (Gaur et al., 2019). According to a study by Kaupins and Coco (2017), especially monitoring heart rates might be critical from an ethical point of view and raises many questions and technology challenges.

\section{Conclusions}

The IoT is about to witness rapid change and will gradually become an integrated component of the workplace. We can presume that this technology will have serious implications on organizational activities, especially in the way human resources are being managed. The gradual development and application of the IoT in HRM is discernable, since the IoT generates an unparalleled amount of data related to people.

The present paper provides a novel perspective on how the application of the IoT can be used to improve core HR practices. The concept of IoT is discussed, which is considered being a new technological revolution, allowing people and things to be connected at any place and any time, ideally using any service and any network. Although the IoT certainly creates many new possibilities, there are various challenges arising from continuous automation and digitization. These challenges are outlined by elaborating on issues related to data management, data mining, privacy, and security.

This paper reveals that only limited research on the application of the IoT in the context of HRM is existing, although a major significant of technology for HRM can be constituted. HR technology can be understood as an intersection of HR data, software, and hardware. Changes in all the three components can be expected when applying the IoT in HRM. Based on the assumption that the IoT provides new possibilities for HRM, this paper elaborates on six HR practices, including workforce planning, recruitment, performance management, training and development, HR Analytics, and health management.

Besides many opportunities and possibilities, the challenge is to design workplace IoT applications that are offering value for the employees, even though the main may be improving employee performance.

This paper enriches the current discussion on the application of the IoT in HRM by providing an overview of the most relevant studies dealing with this theme. Previous studies addressed the impact of the IoT on only some of the core HR practices. In comparison, this review offers a more holistic overview and discusses the potential of the IoT for six core HR practices in more detail. While most of the research discussing IoT in the context of HRM is more conceptual, the present paper creates knowledge of how the IoT can be applied in various HR processes. It offers business managers and leading HR managers a prospect on the development of HRM in a digital future, as well as a starting point on how to use the advantages of IoT within HRM in their own organizations. This paper also raises ethical concerns, which should be addressed by politics to set regulations, as well as business managers before applying IoT.

For future research, this paper offers directions on HR practices in the context of the IoT. Quantitative and empirical research should be aimed at generating knowledge on actual applications and consequences of the IoT in HRM.sM

\section{References}

Andersson, P., \& Mattsson, L. G. (2015). Service innovations enabled by the "internet of things". IMP Journal, 9(1), 85-106. https://doi.org/10.1108/IMP-01-2015-0002

Atzori, L., lera, A., \& Morabito, G. (2010). The Internet of Things: A survey. Computer Networks, 54(15), 2787 2805. https://doi.org/10.1016/j.comnet.2010.05.010

Baldini, G., Botterman, M., Neisse, R., \& Tallacchini, M. (2018). Ethical design in the Internet of Things. Science and Engineering Ethics, 24, 905-925. https://doi.org/10.1007/s11948-016-9754-5

Barman, A., \& Das, M. K. (2018). Internet of Things (loT) as the future smart solution to HRM. In RDA International Conference. Sibsager.

Bauk, S., Dlabač, T., \& Škurić, M. (2018). Internet of Things, high resolution management and new business models. In 23rd International Scientific-Professional Conference on Information Technology, (pp. 1-4). https://doi.org/10.1109/SPIT.2018.8350850

Bersin, J., Mariani, J., \& Monahan, K. (2016). Will loT technology bring us the quantified employee? The Internet of Things in human resources. Retrieved March 19, 2021, from https://www2.deloitte.com/content/dam/insights/us/articl es/people-analytics-iot-humanresources/ER 3104 loT Human-capital vFINAL.pdf

Bondarouk, T., Parry, E., \& Furtmueller, E. (2017). Electronic HRM: four decades of research on adoption and consequences. The International Journal of Human Resource Management, 28(1), 98-131. https://doi.org/10.1080/09585192.2016.1245672

Borgia, E. (2014). The Internet of Things vision: Key features, applications and open issues. Computer Communications, 54, 1-31. https://doi.org/10.1016/j.comcom.2014.09.008 
Boxall, P., \& Purcell, J. (2003). Strategy and human resource management. New York: Palgrave Macmillan.

Charmonman, S., Mongkhonvanit, P., Dieu, V. N., \& Linden, N. (2015). Applications of Internet of Things in elearning. International Journal of the Computer, the Internet and Management, 23(2), 1-4.

Dash, D., Farooq, R., Panda, J. S., \& Sandhyavani, K. V. (2019). Internet of Things (IoT): the new paradigm of HRM and skill development in the fourth industrial revolution (industry 4.0). IUP Journal of Information Technology, 15(4), 7-30.

Dlodlo, N. (2012). The Internet of Things technologies in teaching, learning and basic education management. In Proceedings of Southern African Computer Lecturers' Association 2012 (SACLA 2012).

Elmaghraby, A. S., \& Losavio, M. M. (2014). Cyber security challenges in smart cities: Safety, security and privacy. Journal of Advanced Research, 5(4), 491-497. https://doi.org/10.1016/j.jare.2014.02.006

Fleisch, E. (2010). What is the Internet of Things? An economic perspective. Economics, Management, and Financial Markets, 2, 125-157.

Gartner (2014). Gartner says the Internet of Things will transform the data center. Retrieved March 19, 2021, from https://iot.do/gartner-says-internet-things-willtransform-data-center-2014-03

Gaur, B., Shukla, V. K., \& Verma, A. (2019). Strengthening People Analytics through Wearable IOT Device for Real-Time Data Collection. 2019 International Conference on Automation, Computational and Technology Management (ICACTM), 555-560. https://doi.org/10.1109/ICACTM.2019.8776776

Gluhak, A., Krco, S., Nati, M., Pfisterer, D., Mitton, N., \& Razafindralambo, T. (2011). A survey on facilities for experimental internet of things research. IEEE Communications Magazine, 49(11), 58-67. https://doi.org/10.1109/MCOM.2011.6069710

Guillemin, P., \& Friess, P. (2009). Internet of Things strategic research roadmap. The Cluster of European Research Projects, Technical Report. Retrieved March 19, 2021, from https://sintef.brage.unit.no/sintefxmlui/bitstream/handle/11250/2430372/SINTEF\%2BS1 3363.pdf?sequence=2

Hassan, Z. \& Ali, H., \& Badawy, M. (2015). Internet of Things (IOT): Definitions, challenges, and recent research directions. International Journal of Computer Applications, 128(1), 975-8887. https://doi.org/10.5120/ijca2015906430

Hewlett Packard (2014). HP study reveals 70 percent of Internet of Things devices vulnerable to attack. Retrieved March 19, 2021, from https://www8.hp.com/us/en/hp-news/pressrelease.html?id=1744676\#.YFRkEdwxlhE

lannarelli, B. (2009). Just-in-time training (JITT) and its implications for teaching and learning. In P. Rogers, G. Berg, J. Boettcher, C. Howard, L. Justice, \& K. Schenk (Eds.), Encyclopedia of distance learning (pp. 12971305). Hershey: Information Science Reference. https://doi.org/10.4018/978-1-60566-198-8.ch186

Insights Team (2017). Why collaboration is essential for successful loT implementation. Retrieved March 19, 2021, from https://www.forbes.com/sites/ insightshitachi/2017/12/18/why-collaboration-is-essential-forsuccessful-iot-implementation/\#27effdde10e0
ITU (2012). Next generation networks - frameworks and functional architecture models. In Series Y: Global Information Infrastructure, Internet Protocol Aspects and Next-Generation Networks, Telecommunication Standardization Sector of ITU. Retrieved March 19, 2021, from https://www.itu.int/rec/T-REC-Y.2060201206-I/en

Kaupins, G., \& Coco, M. (2017). Perceptions of Internet-ofthings surveillance by human resource managers. SAM Advanced Management Journal, 82, 53-64.

Kremer, K. (2018). HR analytics and its moderating factors. Vezetéstudomány-Budapest Management Review, 49(11), 62-68. https://doi.org/10.14267/VEZTUD.2018.11.07

Kreps, D., \& Kimppa, K. (2015). Theorizing Web 3.0: ICTs in a changing society. Information Technology and People, 28(4), 726-741. https://doi.org/10.1108/lTP-09-2015-0223

Lee, I., \& Lee, K. (2015). The Internet of Things (IoT): Applications, investments, and challenges for enterprises. Business Horizons, 58(4), 431-440. https://doi.org/10.1016/i.bushor.2015.03.008

Lepak, D. P., Liao, H., Chung, Y., \& Harden, E. E. (2006). A conceptual review of human resource management systems in strategic human resource management research. In J. J. Martocchio (Ed.), Research in personnel and human resources management (pp. 217271). Bingley: Emerald Group Publishing. https://doi.org/10.1016/S0742-7301(06)25006-0

Manyika, J., Chui, M., Brown, B., Bughin, J., Dobbs, R., Roxburgh, C., \& Byers, A. H. (2011). Big Data: The next frontier for innovation, competition, and productivity. McKinsey Global Institute. Retrieved March 19, 2021, from https://www.mckinsey.com/businessfunctions/mckinsey-digital/our-insights/big-data-thenext-frontier-for-innovation

Mohanty, S., \& Mishra, P. C. (2020). Framework for understanding Internet of Things in human resource management. Espacios, 41(12), 3-15.

Nihan, C. E. (2013). Healthier? More efficient? Fairer? An overview of the main ethical issues raised by the use of ubicomp in the workplace. Advances in Distributed Computing and Artificial Intelligence Journal, 2(4), 2940.

Ostroff, C., \& Bowen, D. E. (2000). Moving HR to a higher level: HR practices and organizational effectiveness. In K. J. Klein, \& S. W. J. Kozlowski (Eds.), Multilevel theory, research, and methods in organizations: Foundations, extensions, and new directions (pp. 211266). San Francisco: Jossey-Bass.

Pathak S. \& Solanki V. K. (2021) Impact of Internet of Things and artificial intelligence on human resource development. In Balas V. E., Solanki V. K., Kumar R. (Eds.), Further Advances in Internet of Things in Biomedical and Cyber Physical Systems. Intelligent Systems Reference Library, 193. Springer, Cham. https://doi.org/10.1007/978-3-030-57835-0 19

Rose, K., Eldridge, S., \& Chapin, L. (2015). The internet of things: An overview. The Internet Society (ISOC), 1-50.

Shin, D. (2014). A socio-technical framework for Internet-ofThings design: A human-centered design for the Internet of Things. Telematics and Informatics, 31(4), 519-531. https://doi.org/10.1016/j.tele.2014.02.003 
Solanas, A., Patsakis, C., Conti, M., Vlachos, I., Ramos, V., Falcone, F., \& Martínez-Ballesté, A. (2014). Smart health: A context-aware health paradigm within smart cities. IEEE Communications Magazine, 52(8), 74-81. https://doi.org/10.1109/MCOM.2014.6871673

Spath, D., Gerlach, S., Hämmerle, M., Schlund, S., \& Strölin, T. (2013). Cyber-physical system for selforganised and flexible labour utilisation. In 22nd Conference on Production Research.

Stankovic, J. A. (2014). Research directions for the Internet of Things. IEEE Internet of Things Journal, 1(1), 3-9. https://doi.org/10.1109/JIOT.2014.2312291

Stone, D. L., Deadrick, D. L., Lukaszewski, K. M., \& Johnson, R. (2015). The influence of technology on the future of human resource management. Human Resource Management Review, 25(2), 216-231. https://doi.org/10.1016/j.hrmr.2015.01.002

Strohmeier, S. (2020). Smart HRM - a Delphi study on the application and consequences of the Internet of Things in Human Resource Management. The International Journal of Human Resource Management, 31(18), 2289-2318. https://doi.org/10.1080/09585192.2018.1443963

Swan, M. (2012). Sensor mania! The Internet of Things, wearable computing, objective metrics, and the quantified self 2.0. Journal of Sensor and Actuator Networks, 1(3), 217-253. https://doi.org/10.3390/jsan1030217

Thoben, K. D., Wiesner, S., \& Wuest, T. (2017). Industrie 4.0 and smart manufacturing - A review of research issues and application examples. International Journal of Automation Technology, 11(1), 4-16. https://doi.org/10.20965/ijat.2017.p0004

\section{$\triangle$ Correspondence}

\section{Kristian Kremer}

Faculty of Business and Economics, University of Pécs Rákóczi út 80, 7622, Pécs, Hungary

E-mail: kristian.kremer@gmx.de
TRUSTe (2014). TRUSTe Internet of Things privacy index US edition. Retrieved March 19, 2021, from https://www.ipsos.com/ipsos-mori/en-uk/truste-internetthings-privacy-index

Venkatesh, A. N. (2017). Connecting the dots: Internet of Things and human resource management. American International Journal of Research in Humanities, Arts and Social Sciences, 17(1), 21-24.

Vivekananth, P. (2016). The impact of Internet of Things (IOT) in human resource management. International Journal of Management (IIJM), 4(9), 1-3.

Waber, B. (2013). People analytics: How social sensing technology will transform business and what it tells us about the future of work. Upper Saddle River: FT Press.

Weinberger, M., Bilgeri, D., \& Fleisch, E. (2016). IoT business models in an industrial context. atAutomatisierungstechnik, 64(9), 699-706. https://doi.org/10.1515/auto-2016-0054

Winter, J. S. (2014). Surveillance in ubiquitous network societies: Normative conflicts related to the consumer in-store supermarket experience in the context of the Internet of Things. Ethics and Information Technology, 16, 27-41. https://doi.org/10.1007/s10676-013-9332-3

Yang, L., Yang, S. H., \& Plotnick, L. (2013). How the internet of things technology enhances emergency response operations. Technological Forecasting and Social Change, 80(9), 1854-1867. https://doi.org/10.1016/j.techfore.2012.07.011 